ICRDET-2021, February 26-27, 2021, AICE, Jaipur, India

International Journal of Technical Research \& Science (Special Issue) ISSN No.:2454-2024 (online)

\title{
TENSILE TESTING OF ALSIC COMPOSITE MATERIALS AND ITS VALIDATION USING ANSYS
}

\author{
Bhavana Mathur, Prashant Kumar \\ E-Mail Id: bhavana.mathur@anandice.ac.in \\ Department of Mechanical Engineering, Anand International College of Engineering, Kanota Jaipur \\ Rajasthan, India
}

Abstract- Aluminium Silicon Carbide (AlSiC) composite materials are used in the electronics industries and other manufacturing companies hence, manufacturing of $\mathrm{AlSiC}$ composite materials with the right properties for different applications are vital to most industries. The challenge of testing the same specimens for different properties remains, because most of the tests carried out are destructive. Hence, the use of ANSYS finite element simulation software for the design and analysis of a flat bar specimen. Loads between $3 \mathrm{kN}$ to $21 \mathrm{kN}$ were applied on the specimen since it is within the operating limit of a Universal Tensile Testing Machine (UTTM), while both ends are fixed. The AlSiC composite materials used in this study have a composition of 63 vol\% $\mathrm{Al}$ (356.2) and $37 \mathrm{vol} \% \mathrm{SiC}$ and, the results showed that stress was directly proportional to strain. While the calculated Young's modulus from the stress versus strain plot was approximately $167 \mathrm{GPa}$ for the different tensile loads applied. In addition, the total deformation of the AlSiC composite material increased as the load was increased. Also, the highest deformation of the material was observed around the centre of the test specimen. This is synonymous with the failure observed in practical testing of specimens.

Keywords: AlSiC, tensile load, aluminium MMC, stress analysis, deformation, ANSYS.

\section{INTRODUCTION}

The quest for alternative materials as against the traditional materials of aluminium and copper in the electronic and automobile industries are on the increase in recent years (Ekpu et al., 2011). Aluminium metal matrix composite (Al-MMC) materials are readily been researched because of the potential properties the materials exhibits, such as light weight, high strength, stiffness, greater resistance to corrosion, oxidation and wear (Meena et al., 2013). Agnihotri and Dagar (2017), also stated that aluminium and its alloys possess excellent properties such as low density, good plasticity and ductility. The researchers noted that the mechanical properties of the cast metal matrix composites can be greatly impacted by the production process variables such as stirring speed, holding temperature, the position of the impeller, and size of the impeller. Their research inferred that the mechanical properties of the AlSiC composite material, such as the hardness and tensile strength were improved by the introduction of Silicon Carbide (SiC) particulates to the Aluminium ( $\mathrm{Al}$ ) metal matrix. Also, increase in the percentage of $\mathrm{SiC}$ particulates reduces the wear rate of the Metal Matrix Composites (MMCs). Researchers have studied and investigated different ways of producing AlSiC composite materials. Amongst the most used method is the stir casting process/technique (Kumar et al., 2019; Babalola et al., 2018; Occhionero et al., 2020). Adebisi and Ndaliman (2016), used stir casting technique to investigateto keep the hands from drying out, should one's hands require washing more than a few times per day. People may catch diseases or pass diseases on to other people if they do not all keep their hands clean. Food prepared with dirty hands can carry diseases [4]. Therefore, to protect microbial culture, ourselves and the community, we also have to keep in mind, about proper hand washing in daily life. The aim of this research is to give public health knowledge about proper hand washing to the community. Silicon Carbide particles (Al-SiCp) composite materials. From their developed model, it was inferred that out of the four factors studied, stirring speed was the most influential factor on the properties of Al-SiCp composite material. In another study by Sujan et al., (2012), stir casting was used to develop the test specimens. In their research, it was observed that increasing the silicon carbide particles in the aluminium metal matrix improved the mechanical properties of the produced composite materials. Also, the decrease in elongation and fracture toughness of aluminium silicon carbide composite material was attributed to the brittleness of the silicon carbide particles. Adeosun et al., (2013), investigated the effect of mould temperature and different cooling method on the mechanical properties of stir cast AlSiC composite materials. It was inferred that the temperature of the mould before casting has a significant effect on the mechanical properties of the cast composite materials. They observed that, the higher the mould temperature the lower the tensile strength and hardness of the composite materials. Also, it was inferred that the quench samples of the composite materials exhibited higher tensile strength than the samples annealed for the same mould temperature $\left(200^{\circ} \mathrm{C}\right)$.

Teng et al., (2016), studied $\mathrm{Al}-50 \% \mathrm{SiC}$ composites material with different $\mathrm{SiC}$ particle sizes produced by powder metallurgy. The effect of SiC particle sizes and annealing on the properties of the composites were analysed. The researchers inferred that the $\mathrm{SiC}$ particles were evenly distributed in the $\mathrm{Al}$ matrix. They reported that, the thermal conductivity (TC) and coefficient of thermal expansion were improved by coarse SiC particulates, while the flexural strength and coefficient of thermal expansion were improved and reduced respectively by fine $\mathrm{SiC}$ particles in the composite material. Most of the researches carried out on AlSiC were tested by destructive methods either tensile or compact testing (Sasikumar and Singh 2015; Pawar and Utpat 2014). These testing methods made it difficult to practically analyse the same test sample under different load conditions. Testing the same specimen would have been helpful in ensuring that the properties gotten from the various tests were accurate and reliable. Hence, the need for finite element analyses of the effect of tensile load 
ICRDET-2021, February 26-27, 2021, AICE, Jaipur, India

International Journal of Technical Research \& Science (Special Issue) ISSN No.:2454-2024 (online)

on the mechanical properties of AlSiC composite materials using ANSYS design modeller. Finite element methods have been used to analyse the effectiveness of applications produced by AlSiC composite materials. Pawar and Utpat (2014), used the properties gotten from their tests of aluminium silicon carbide composite materials to develop a spur gear using CATIA and ANSYS design modeller. The finite element analyses demonstrated that AlSiC composite material is a good option for power transmission gears. Nandish et al., (2017), developed a connecting rod using AlSiC composite material with the addition of ash. The connecting rod was analysed using finite element analysis parameters. The results from the investigation showed that the proposed composite material had less weight and was more rigid than the traditional aluminium material used to produce connecting rods. The present research work is being carried out to demonstrate the strength of AlSiC composite materials in the electronic and automobile industries.

\section{MATERIALS AND METHODS}

\subsection{Model Description}

The tensile test specimen was created using ANSYS design modeller. A 3D flat bar was designed for the purpose of this investigation. The schematic diagram of the tensile test sample is shown in Figure 1. All dimensions of the test specimen are in millimetres $(\mathrm{mm})$ and, $\mathrm{H} 3$ and $\mathrm{H} 4$ are equal in length (53 mm), while $\mathrm{H} 1$ and $\mathrm{H} 2$ also have same length $(22 \mathrm{~mm})$. The thickness of the test specimen is $5 \mathrm{~mm}$, while the width on the edge is $15 \mathrm{~mm}$. Meena et al., (2013) used a circular test specimen with similar length for their investigation, while Sasikumar and Singh 2015 used a flat bar for their tensile analysis.

\subsection{Materials, Load and Boundary Conditions}

The Aluminium Silicon Carbide composite material having a composition of $63 \mathrm{vol} \% \mathrm{Al}(356.2)$ and $37 \mathrm{vol} \%$ $\mathrm{SiC}$ particulates was used in this study. Other material properties used for AlSiC composite materials were extrapolated from literature (Occhionero et al., 2020). The conditions of a Universal Tensile Testing Machine (UTTM) for practical test specimens were replicated to the best of the simulation software capability. The test specimen was fixed on both ends. as it would have been if using UTTM. In addition, tensile loads were applied from $3000 \mathrm{~N}$ to $21000 \mathrm{~N}$ at an interval of $3000 \mathrm{~N}$ as obtained in Babalola et al., (2018). This is consistent with the tensile loads of a UTTM

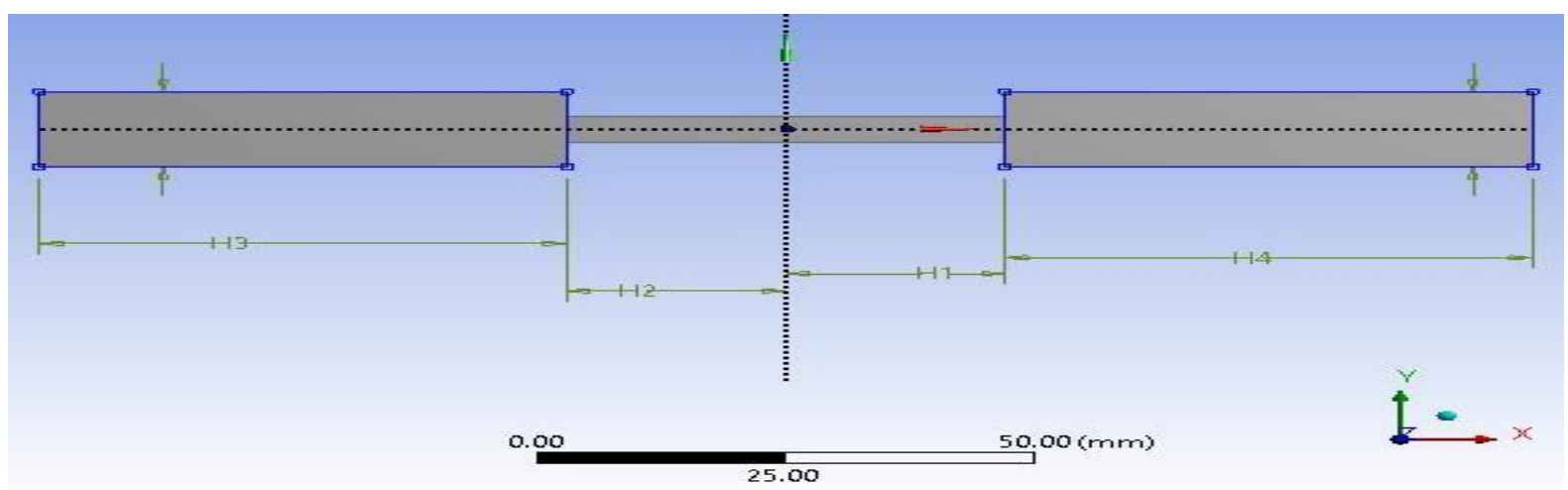

Fig. 2.1 Tensile test specimen.

\section{RESULTS AND DISCUSSION}

\subsection{Mesh}

According to the mesh dependency study done by Ekpu (2019), it was inferred from the work that a mesh size between $20 \%$ and $40 \%$ of the initial size of a model is ideal for having effective results in simulation work done in ANSYS. With thisinformation, the present test sample was meshed at $25 \%$ of theinitial size of the model. This resulted in 24341 nodes and 4704 elements. Figure 2 shows the meshed results used in this investigation.

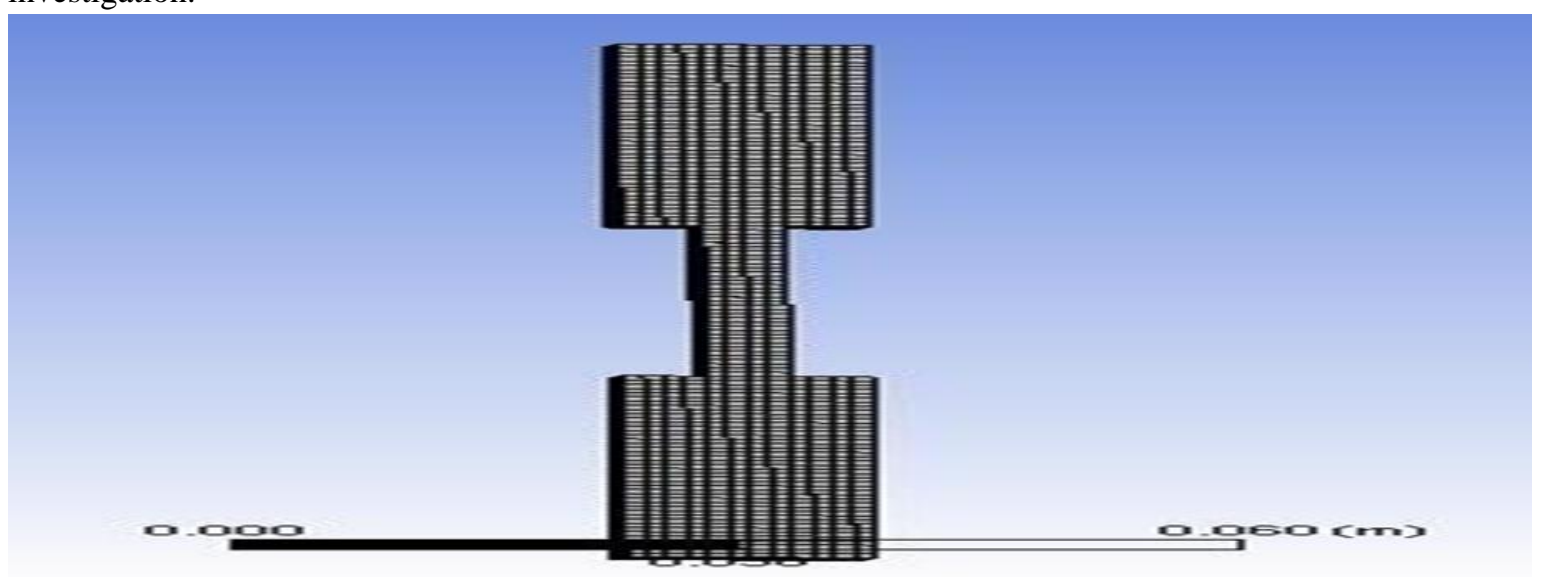

Fig. 3.1 Mesh with 24341 nodes and 4704 elements

DOI Number: https://doi.org/10.30780/specialissue-ICRDET-2021/009 


\subsection{Deformation Analysis}

The deformation of materials under loads are inevitable in most tensile analysis. Figure 3 presents the total deformation of the test specimen. From the figure, it is clearly observed that the most deformation is around the centre area of the specimen. This shows that the test specimen will fail around this region. In the work carried out by Meena et al., (2013), the test specimens were clearly seen to have failed around the centre after tensile loads were applied. This supports the deformationseen in Figure 3. In adfition, the least amount of deformation could be seen at the area where the test specimen had fixed support. In other words, the highest deformation $(4.4195 \mathrm{x}$ $\left.10^{-6} \mathrm{~m}\right)$ of the specimen is represented by the red contour legend in $F$ Figure 3 , while the lowest deformation $(0 \mathrm{~m})$ is representedby the blue contour legend

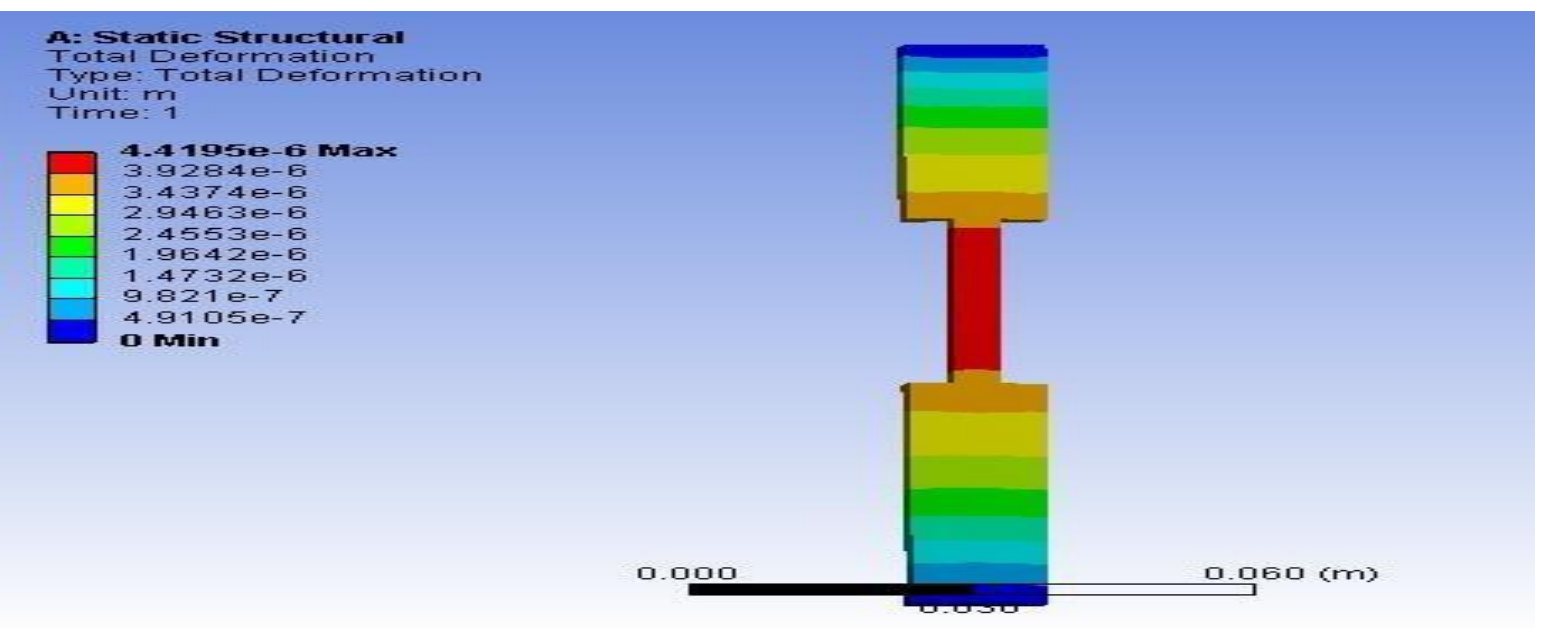

Fig. 3.2 Total deformation at $3 \mathrm{kN}$.

Fig. 3.2 presents the graph of force $(\mathrm{N})$ against total deformation $(\mathrm{m})$. The graph shows that as the force is being increased, the total deformation increased proportionately. Therefore, the higher the tensile load on the AlSiC composite material the larger the damage. When a force of $21 \mathrm{kN}$ was applied on the test specimen, a resultant total deformation of $3.09 \times 10^{-5} \mathrm{~m}$ was recorded. While at a tensile load of $3 \mathrm{kN}$, the total deformation recorded was $4.42 \times 10^{-6} \mathrm{~m}$. The difference between the total deformation at $3 \mathrm{kN}$ and $21 \mathrm{kN}$ is about $599 \%$. This difference clearly shows that total deformation is dependent on the amount of load applied to the test specimen.

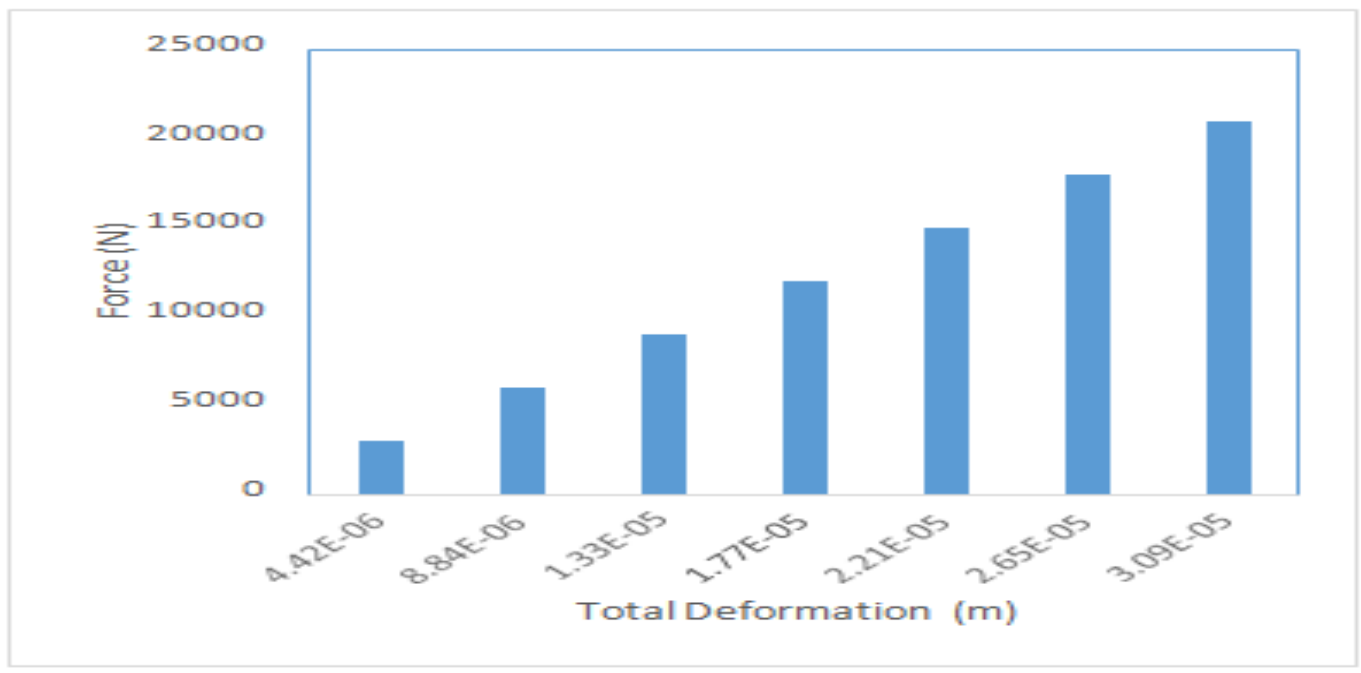

Fig. 3.3 Force vs total deformation.

\subsection{Analysis of Stress and Strain}

From the tensile test carried out on the designed specimen, stresses and strains were recorded. Eqs. (1) and (2) give the expression for calculating stress and strain respectively

$$
\begin{aligned}
& \text { Stress }=\frac{F}{A} \\
& \text { Strain }=\frac{\Delta L}{L}
\end{aligned}
$$

where $\mathrm{F}$ is force in Newton, $\mathrm{A}$ is Area in metre squared, $\mathrm{L}$ is length in metres and $\Delta \mathrm{L}$ is the change in length. Figure 5 presents the stress contour plot of the test specimen. From the figure, it is observed that the highest amount of stress are concentrated around the fixed support regions. The highest stress on the specimen when a load of $3000 \mathrm{~N}$ was applied, could be seen to be $29.625 \mathrm{MPa}$. In addition, the red contour legend represents the highest stress on the specimen, while the blue contour legend represents the lowest stress 


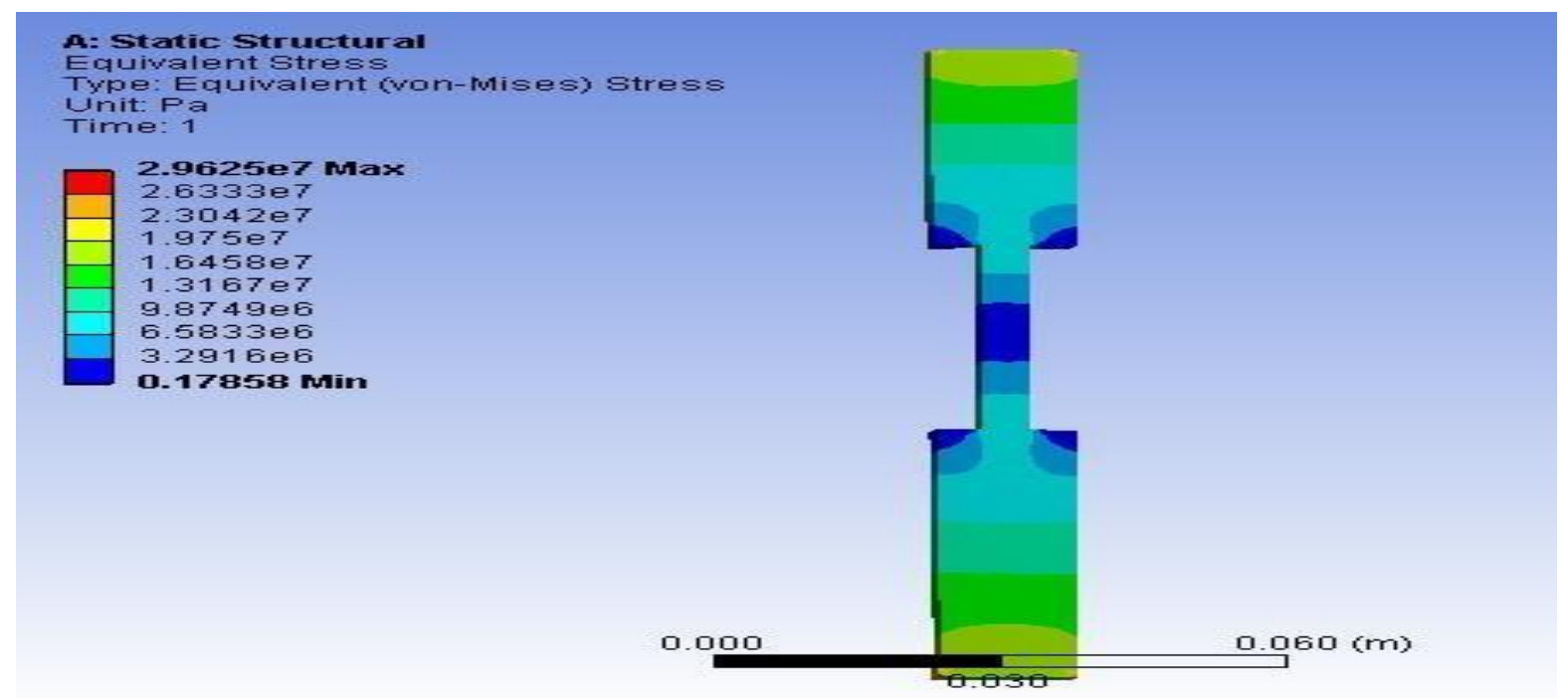

Fig. 3.4 Stress contour Plot at $3 \mathrm{kN}$

Fig. 3.4, presents the strain contour plots for the specimen studied and, it is clearly observed that the contour with higher concentration of strain is on the fixed support regions. This was expected based on the tensile analyses carried out. The blue contour legend signify the minimum strain, while the red contour legend signifies the maximum strain. In addition, when a load of $3000 \mathrm{~N}$ was applied on the designed specimen, a strain of $1.7739 \times 10^{-04} \mathrm{~m} / \mathrm{m}$ was recorded. It was also observed that there was distribution of stresses and strains in the entire body of the specimen.

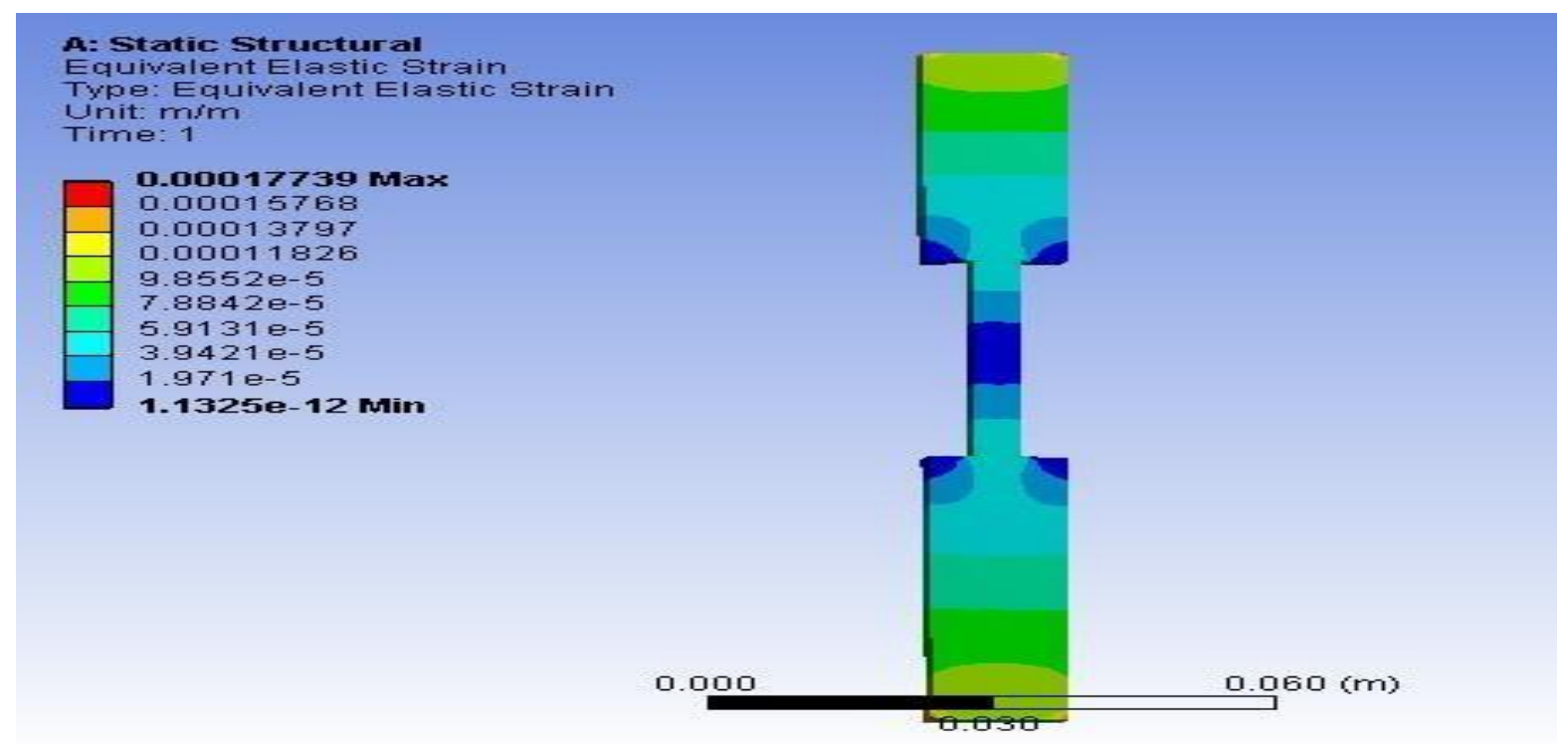

Fig. 3.5 Strain contour plot at $3 \mathrm{kN}$

Fig. 3.5 presents the plot of stress against strain based on the results of varying the tensile load used in this study. From the figure, it was observed that as the force is increased, the stress and strain increased proportionately relative to each other in the analysis. The highest stress of approximately $207 \mathrm{MPa}$ was observed at a force of $21 \mathrm{kN}$, while the lowest stress of approximately $29.62 \mathrm{MPa}$ was observed at a force of $3 \mathrm{kN}$. Likewise, the maximum and minimum strains at $21 \mathrm{kN}$ and $3 \mathrm{kN}$ were observed to be approximately 0.00124 $\mathrm{m} / \mathrm{m}$ and $0.000177 \mathrm{~m} / \mathrm{m}$ respectively.

Since stress was directly proportional to strain based on the results of the stress versus strain analysis in this research, it is expected that if the gradient at any point on the stress against strain plot is taken, the slope (Young's Modulus) should be the same all through.

$$
\text { Young's Modulus }=\frac{\text { Stress }}{\text { Strain }}
$$

When the calculation based on Equation 3 was carried out for each of the points plotted on the stress versus strain plot, a Young's Modulus of approximately $167 \mathrm{GPa}$ was arrived at. The resulting values of Young's Modulus were plotted against force as seen in Figure 8. From Figure 8, it was observed that the Young's modulus for each of the forces applied were approximately the same. It can be inferred based on this study that, an increase in the applied force have no effect on the modulus of the AlSiC composite material specimen, but can adversely affect the total deformation. The results from this investigation clearly shows that the load and boundary conditions used in this study are what is obtainable from a Universal Tensile Testing Machine (Sasikumar and Singh 2015). 
ICRDET-2021, February 26-27, 2021, AICE, Jaipur, India

International Journal of Technical Research \& Science (Special Issue) ISSN No.:2454-2024 (online)

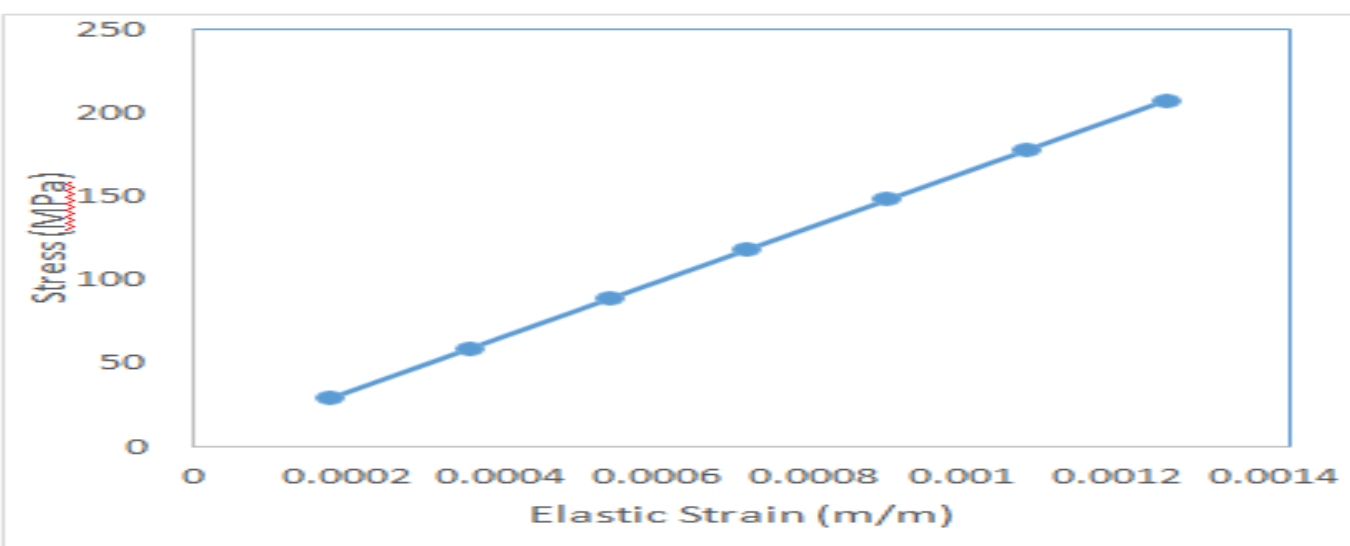

Fig. 3.6 Stress vs. strain plot at varying force

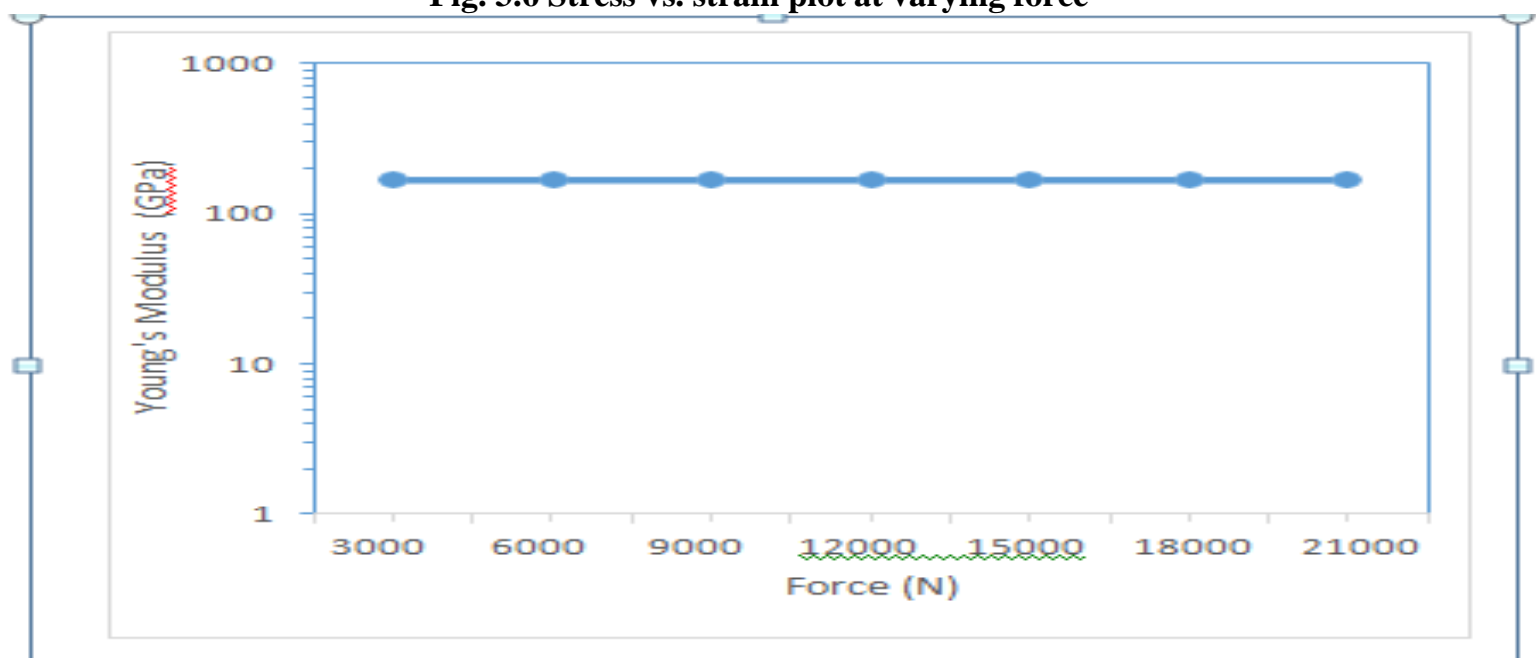

Fig. 3.7 Young's Modulus versus force

\section{CONCLUSION}

This work analyses the impact of tensile load on aluminium silicon carbide (63 vol\% $\mathrm{Al}(356.2)$ and 37 vol\% $\mathrm{SiC})$ composite material. The results from the ANSYS simulation clearly showed that increased load affects the total deformation of the material studied. Also, the Young's modulus calculated from the stress versus strain plot was equal at every gradient point. This conclusion supports the notion that the load and boundary conditions used in the research is synonymous to those obtained from UTM. This research could serve as a reference material to researchers producing AlSiC composite materials by stir casting method or process for electronic and automobile industries.

\section{REFERENCES}

[1] Adebisi, A. A. and Ndaliman, M. B. (2016). Investigationof Analytical Model Development for Processing Aluminum Silicon Carbide Composite Material. Journal of NIMechE. 6 (1): 71-80.

[2] Adeosun, S. O.; E. I. Akpan and D. Abiodun. (2013). Mould Temperature and Mechanical Properties of Cast Aluminum-Silicon Carbide Composite. International Journal of Materials and Chemistry, 3 (4): 75 83.

[3] Agnihotri, R. and Dagar, S. (2017). Mechanical Properties of Al-SiC Metal Matrix Composites Fabricated by Stir Casting Route. Research in Medical and EngineeringSciences. 2 (5): 178-183.

[4] Babalola, P. O.; C. A. Bolu; A. O. Inegbenebor and O. Kilanko. (2018). Graphical Representations of Experimental and ANN Predicted Data for Mechanical and Electrical Properties of AlSiC Composite Prepared by Stir Casting Method. IOP Conf. Series: Materials Science and Engineering, 413012063 doi:10.1088/1757-899X/413/1/012063.

[5] Ekpu, M.; R. Bhatti; N. Ekere; S. Mallik; E. Amalu and K. Otiaba. (2011). Investigation of effects of heat sinks on thermal performance of microelectronic package. 3rd IEEE International Conference on Adaptive Science and Technology(ICAST 2011), Abuja, 2011, 127-132, doi: 10.1109/ICASTech.2011.6145164.

[6] Ekpu, M. (2019). Finite Element Analysis of the Effect ofFin Geometry on Thermal Performance of Heat Sinks in Microelectronics. Journal of Applied Sciences and Environmental Management. 23 (11): 20592063.

[7] Kumar, S. S.; M. Uthayakumar; S. T. Kumaran; T. Varol and A. Canakci. (2019). Investigating the surface integrity of aluminium based composites machined by EDM. Defence Technology. 15 (3): 338-343. 
ICRDET-2021, February 26-27, 2021, AICE, Jaipur, India

International Journal of Technical Research \& Science (Special Issue) ISSN No.:2454-2024 (online)

[8] Meena, K. L.; A. Manna; S. S. Banwait and D. Jaswanti. (2013). An Analysis of Mechanical Properties of the Developed Al/SiC-MMC's. American Journal of Mechanical Engineering, 1 (1): 14-19.

[9] Nandish, B.; K. P. Muthanna and M. B. Kaveriappa. (2017). Finite Element Analysis of Aluminium Based Composite as a Material for Connecting Rod. Applied Mechanics and Materials, 867 (1): 228-232.

[10] Pawar, P. B. and Utpat, A. A. (2014). Development of Aluminium Based Silicon Carbide Particulate Metal Matrix Composite for Spur Gear. Procedia Materials Science, 6 (2014): 1150-1156.

[11] Sasikumar, T. and Singh, R. R. B. (2015). Evaluating the mechanical characteristics of Al/SiC metal matrix composites (MMC) using Infrared thermographic Images. 12th International Conference on Quantitative Infrared Thermography 2015, July 6-10, Mahabalipuram, India (QIRT 2015): 1-10.

[12] A. Maleque and M. Y. Ali. (2012). Aluminum-Silicon Carbide Composites for Enhanced Physio-Mechanical Properties. Advance Materials Research, 576 (2012): 370-373. Teng, F.; K. Yu; J. Luo; H. Fang; C. Shi; Y. Dai and H. Xiong. (2016). Microstructures and properties of Al-50\%SiC composites for electronic packaging applications. Transactions of Nonferrous Metals Society of China. 26 (2016): 2647-2652. 